\title{
Test Accuracy of CT-Scan for the Detection of Malignant Liver Mass
}

\author{
Wahida Begum1, Biswajit Bhowmik², Khondker Shaheed Hussain³, Md. Abdullah Yusuf ${ }^{4}$ \\ ${ }^{1}$ Department of Neuroradiology \& Imaging, National Institute of Neurosciences \& Hospital, Dhaka, Bangladesh \\ ${ }^{2}$ Department of Radilogy \& Imaging, Banghabandhu Sheikh Mujib Medical University, Dhaka, Bangladesh \\ ${ }^{3}$ Department of Cardiology, National Institute of Cardiovascular Diseases, Dhaka, Bangladesh \\ ${ }^{4}$ Department of Microbiology, National Institute of Neurosciences \& Hospital, Dhaka, Bangladesh \\ Email: wahidabegum17@yahoo.com, palash48@gmail.com, drshaheed1962@yahoo.com, \\ ayusuf75@yahoo.com
}

Received 27 March 2015; accepted 1 June 2015; published 5 June 2015

Copyright (C) 2015 by authors and Scientific Research Publishing Inc.

This work is licensed under the Creative Commons Attribution International License (CC BY).

http://creativecommons.org/licenses/by/4.0/

(c) () Open Access

\section{Abstract}

Background: Detection of malignant liver mass is very important for the treatment modalities. Objective: The purpose of the present study was to establish the usefulness of CT scan in the diagnosis of malignant hepatic mass. Methodology: This cross sectional study was carried out in the Department of Radiology and Imaging at Mymensingh Medical College Hospital (MMCH), Mymensingh, Banghabandhu Sheikh Mujib Medical University (BSMMU), Dhaka and Dhaka Medical College Hospital (DMCH), Dhaka during the period of 1st January 2006 to 31st December 2007. Patients admitted in the Department of Medicine and Department of Hepatobiliary of MMCH, BSMMU, and DMCH with the clinical diagnosis of fever, abdominal pain, anorexia, nausea/vomiting, loss of appetite, jaundice, weight loss and ascites were selected as study population. CT scan and histopathology were performed to all the patients. Result: A total number of 50 patients were recruited for this study. Mean age of all patients was $51.28 \pm 14$ years with a range of 17 year to 78 years. Among all patients 28 had multiple lesion, of them $71.4 \%$ was malignant and $28.6 \%$ was benign. On the other side 22 patients had solitary lesion, of them $36.4 \%$ was malignant and $63.6 \%$ was benign ( $p<0.05$ ). Sensitivity of CT to diagnose malignant lesion was $96.4 \%$, specificity $86.4 \%$, accuracy $92 \%$, positive predictive value $90 \%$ and negative predictive value $95 \%$. Conclusion: CT is a useful diagnostic tool for the detection of malignant hepatic masses.

\section{Keywords}

Test accuracy, CT-Scan, Malignant, Liver Mass 


\section{Introduction}

Malignant liver mass, especially hepatocellular carcinoma (HCC), is the most common primary malignant tumour of the liver representing more than $80 \%$ of all primary hepatic malignancies [1]. It is relatively common in equatorial Africa and Asia, rare in United States [2]. On CT-scan, HCC appears as low density lesions as these are supplied mainly by arterial blood rather than portal venous blood and insufficient blood flow in the hepatic artery contributes to necrosis of hepatic tissue and to further lowering of the density of CT-scan [3]. Computed tomography has been highly useful in detecting liver tumours and in determining their extent. However, with the exception of some hepatic lesions containing calcium, extravasated blood, fat or densely enhanced parts, the CT-scan appearance of liver tumours is similar and nonspecific regardless of their histologic type [4]. Dynamic CT sensitivity has been reported as $80 \%$ and MRI sensitivity as $40 \%$ [5]. Hepatocellular adenoma is the most common benign liver tumours. CT-scan can show a well circumscribed and often encapsulated mass has a low density on non-contest phase, a marked centripetal pattern of enhancement on a phase and a central necrotic area or calcifications [6]. Cystic lesions are readily identified and abscesses are usually distinguished from tumours [7]. The present study was designed to evaluate the role of CT-scan in the evaluation of malignant hepatic mass and was correlated with histopathology.

\section{Materials and Methods}

\subsection{Study Group and Examination Technique}

This cross sectional study was carried out in the Department of Radiology and Imaging of three tertiary care hospitals in Bangladesh named as Mymensingh Medical College Hospital, Mymensingh; Dhaka Medical College Hospital, Dhaka and Banghabandhu Sfheikh Mujib Medical University (BSMMU), Dhaka in collaboration with the Department of Pathology of the same institute for histopathological diagnosis from 1st January 2006 to 31st December 2007 for a period of 2 years. All the clinically suspected patients having hepatic mass at any age with both sexes who were attended in three hospitals were taken as study population as per inclusion and exclusion criteria. Patients having hepatomegaly due to extra hepatic causes, patients who refused to undergo CT-scan, patients who refuse to do biopsy or whose biopsy result was not available and patients having known hypersensitivity reaction to contrast agent were excluded from this study. Purposive sampling technique was used to collect the patients. Prior to the commencement of this study, the research protocol was approved by the ethics review committee of the respective hospital. Each patient was undergone CT examination of hepatobiliary system (HBS) at the Department of Radiology and Imaging. All CT-scan were performed with a third generation CTscan (Siemans). Somatom (2 - 5) mm thick contiguous slice were taken. These scan were obtained using $120 \mathrm{kv}$, $75 \mathrm{~mm}$ and 0.8 see scanning time for 2 slice. Both pre and post contrast were performed. Oral contrast medium was routinely administrated before the examination. Immediately after completion of bolus injection 8mm contiguous slice were obtained through the upper abdomen by CT-scan. All collected biopsy tissues were sent for histopathological examination in the histopathology department of respective hospital and collected reports were compared with CT-scan diagnosis.

\subsection{Statistical Analyses}

Percentages were calculated to find out the proportion of the findings. Further statistical analysis of the results was done by computer software devised as the statistical package for the social sciences (SPSS, windows version 16.0). For the validity of the study outcome sensitivity, specificity, accuracy, positive and negative predictive values were calculated after confirmation of the diagnosis histopathologically. For significance of differences was done using Student's t test and Chi-square test where applicable. Statistical significance was set at p value less than 0.05 and confidence interval was set at $95 \%$ level. All probability values quoted were 2-tailed. The sampling technique was by purposive sampling technique. The $80 \%$ statistical power was taken with a $5 \%$ statistical error. The ultimate sample size was calculated by single group of study population.

\section{Result}

A total number of 50 clinically diagnosed hepatomegaly patients were recruited in the study. The mean $( \pm \mathrm{SD})$ age of the respondents was $51.28( \pm 14.06)$ years. Males $(80.0 \%)$ were more predominant than females $(20.0 \%)$. The male and female ratio was found 4:1. Statistical analysis of patients of both sex has revealed that they were 
within similar age distribution $(\mathrm{p}=0.617)$. Mean age of male was $50.78( \pm 13.68)$ years whereas female was 53.3 $( \pm 16.11)$ years. Age range of the total patients was 17 year to 78 years. Maximum patients were within 470 to 60 years which was 29 (58.0\%) cases (Table 1$)$. Among 50 patients 28 cases were histopathological confirmed as malignant liver mass and the rest 22 were diagnosed as non-malignant liver mass $(\mathrm{p}=0.001)$. Among the 28 histopathological confirmed malignant cases CT-scan has diagnosed 27 (96.4\%) cases as malignant liver mass; whereas 19 (86.4\%) cases were found non-malignant liver mass in both CT-scan and histopathology (Table 2). Sensitivity of CT to diagnose malignant lesion was $96.4 \%$, specificity $86.4 \%$, accuracy $92 \%$, positive predictive value $90.0 \%$ and negative predictive value $95.0 \%$ (Table 3 ). The ROC curve showed a significant value with 0.914 (95\% CI 0.820 to 1.008) (Figure 1).

\section{Discussion}

Hepatic masses come to clinical attention when these are felt by the patient as well as discovered on physical examination by the physician or most commonly detected on diagnostic radiological studies [8]. Technologic-

Table 1. Age and sex distribution of study population $(n=50)$.

\begin{tabular}{cccc}
\hline \multirow{2}{*}{ Age group } & \multicolumn{2}{c}{ Sex } & Total \\
\cline { 2 - 3 } Less than 20 years & Male & Female & $1(2.0 \%)$ \\
20 to 40 years & $0(0.0 \%)$ & $1(10.0 \%)$ & $9(18.0 \%)$ \\
40 to 60 years & $9(22.5 \%)$ & $6(0.0 \%)$ & $11(22.0 \%)$ \\
More than 60 years & $23(57.5 \%)$ & $3(30.0 \%)$ & $50(100.0 \%)$ \\
Total & $8(20.0 \%)$ & $10(100.0 \%)$ & $53.30 \pm 16.11$ \\
Mean \pm SD & $40(100.0 \%)$ & $50.78 \pm 13.68$ &
\end{tabular}

*Student t test was performed to see the level of significance; p value 0.617 .

Table 2. Association of CT-scan and histopathological findings of the liver mass $(\mathrm{n}=50)$.

\begin{tabular}{cccc}
\multirow{2}{*}{ CT-scan diagnosis } & \multicolumn{2}{c}{ Histopathological diagnosis } & Total \\
\cline { 2 - 4 } & Malignant & Not malignant & $30(60.0 \%)$ \\
Malignant & $27(96.4 \%)$ & $3(13.6 \%)$ & $20(40.0 \%)$ \\
Not malignant & $1(3.6 \%)$ & $19(86.4 \%)$ & $50(100.0 \%)$ \\
Total & $28(100.0 \%)$ & $22(100.0 \%)$ &
\end{tabular}

${ }^{*}$ Chi square value $=35.187, \mathrm{df}=1, \mathrm{p}$ value $=0.001$.

Table 3. Test validity parameters of CT-scan for diagnosis of malignant liver masses.

\begin{tabular}{ccc}
\hline Parameters & Value & $95 \%$ CI \\
\hline Sensitivity & $96.4 \%$ & $91.24 \%$ to $101.56 \%$ \\
Specificity & $86.4 \%$ & $76.9 \%$ to $95.9 \%$ \\
PPV & $90.0 \%$ & $81.68 \%$ to $98.32 \%$ \\
NPV & $95.0 \%$ & $88.96 \%$ to $101.04 \%$ \\
Accuracy & $92.0 \%$ & $84.48 \%$ to $99.52 \%$ \\
\hline
\end{tabular}

${ }^{*} 95 \%$ CI = 95\% confidence interval. 


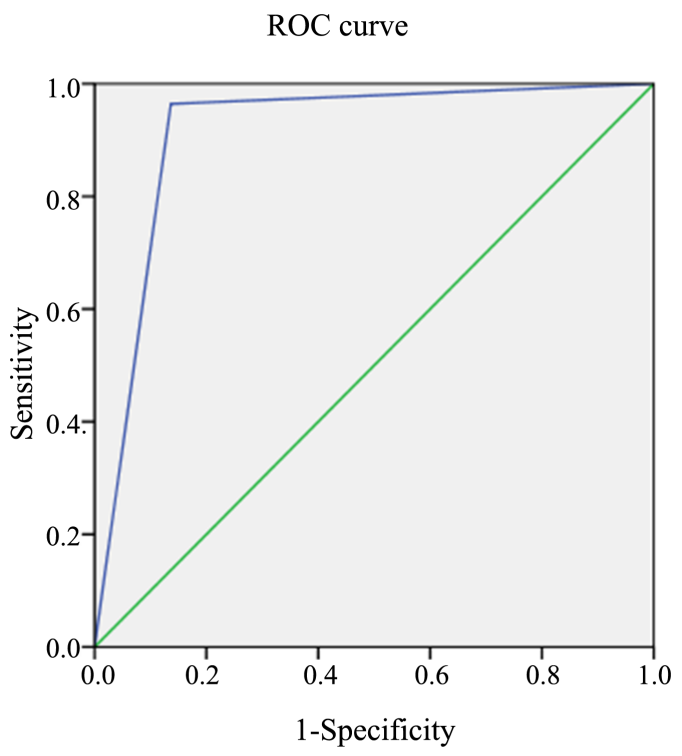

Diagonal segments are produced by ties.

Figure 1. Value of ROC curve: 0.914 (95\% CI 0.820 to 1.008); p value 0.0001 .

advances and the expanded use of imaging modalities have led to the increased documentation of hepatic masses. This study was carried out to determine the accuracy of CT scan examination for the evaluation of hepatic masses and it's correlation with histopathological examinations.

During the study period from 1st January 2006 to 31st December 2007, total 50 cases were studied who had undergone CT examinations of hepatobiliary system. The final diagnosis of hepatic masses was made by histopathological examinations. Mean age of male of present study was 50.78 years with a std. deviation of \pm 13.68 whereas female was 53.3 years with std. deviation of \pm 16.11 years. Age range of the total patients was 17 year to 78 years. Maximum patients were within 40 to 60 years of age group. Statistical analysis of patients of both sex has revealed that they were within similar age distribution ( $p$ value $=0.617$ ). Liver mass can occur in a person of any age; however, the incidence is more common in middle aged and elderly persons [9]. Their study whose age of the patients varies from 20 - 75 years is nearly similar to this present study. Most of the patients were found between 41-50 years. In the USA and Western Europe, HCCs are seldom encountered before the age 60 with male and female ratio of about 6:1 to 8:18. In Africa and Asia this form of cancer occurs in younger individuals often between 20 and 40 year-age with a male: female ratio about 3:1 to 4:1 [10]. Out of 50 patients of present study 40 were male and 10 were female with a male and female ratio 4:1. This result was consistent other studies [7] [9]. In another study [11], it has been reported that male and female ratio of hepatic masses was 6:1. Variation of hepatic masses was seen in different studies conducted in Bangladesh [12] [13].

In case of malignant diseases, twenty seven patients were diagnosed as malignant by CT and confirmed by histopathological evaluation. They were true positive. Three patients were diagnosed as malignant by CT but not confirmed by histopathology. They were false positive. Of 20 patients of benign lesions, which were confirmed by CT, 1 was confirmed as malignant and 19 were benign by histopathology. They were false negative and true negative respectively.

Sensitivity of CT to diagnose malignant lesion was $96.4 \%$, specificity $86.4 \%$, accuracy $92 \%$, positive predictive value $90 \%$ and negative predictive value $95 \%$. Kang et al. [14] reported CT is $88 \%$ sensitivity and $98 \%$ specific in the detection of malignant liver mass. Snow et al. [15] conducted a comparative study of CT, USG and scintigraphy in 94 patients with clinically suspected SOL in liver where CT proved to be the most accurate in detecting masses and assessing the complete extent of intra hepatic disease. In their study CT was found 96\% sensitivity, 86\% specificity and 95\% accuracy in the diagnosis of malignant liver mass. Parveen [16] has observed the sensitivity, specificity and accuracy of CT scan for detecting SOL in liver was $95 \%, 50 \%$ and $81 \%$ respectively. These results were almost consistent with this present study. From the result of the present findings 
as well as findings obtained by a number of investigators, it is apparent that CT scan is ideal and accurate diagnostic imaging modalities for the diagnosis of hepatic masses. There are some limitations of this study. Sample size is small. Furthermore, the purposive sampling was giving a selection bias which was a limitation of the study.

\section{Conclusion}

The results of the present study therefore conclude that CT is a useful modality for the diagnosis of malignant liver masses. Since the CT diagnosis correlates with histopathological connection, it is a sensitive modality on the basis of the above findings.

\section{References}

[1] Adam, A. (2001) The Liver, Biliary Tract, Pancreas, Endocrine System and Lymphoma. In: Grainger R.G., Allison, D., Adam, A. and Dixon, A.K., Eds., Grainger \& Allison's Diagnostic Radiology: A Textbook of Medical Imaging, 4th Edition, Churchill Livingstone, London, 1237-1488.

[2] Teefey, S.A., Hildeboldt, C.C., Dehdashti, F., Siegel, B.A., Peters, M.G., Heiken, J.P., Brown, J.J., McFarland, E.G., Middleton, W.D. and Balfe, D.M. (2003) Detection of Primary Hepatic Malignancy in Liver Transplant Candidates: Prospective Comparison of CT, MR Imaging, US, and PET 1. Radiology, 226, 533-542. http://dx.doi.org/10.1148/radiol.2262011980

[3] Tsukada, K., Takada, T., Miyazaki, M., Miyakawa, S., Nagino, M., Kondo, S., Furuse, J., Saito, H., Tsuyuguchi, T. and Kimura, F. (2008) Diagnosis of Biliary Tract and Ampullary Carcinomas. Journal of Hepato-Biliary-Pancreatic Sciences, 15, 31-40. http://dx.doi.org/10.1007/s00534-007-1278-6

[4] Tse, F., Barkun, J.S., Romagnuolo, J., Friedman, G., Bornstein, J.D. and Barkun, A.N. (2006) Nonoperative Imaging Techniques in Suspected Biliary Tract Obstruction. HPB, 8, 409-425. http://dx.doi.org/10.1080/13651820600746867

[5] Vilgrain, Vr. (2006) Focal Nodular Hyperplasia. European Journal of Radiology, 58, 236-245. http://dx.doi.org/10.1016/j.ejrad.2005.11.043

[6] Ramacciato, G., Nigri, G.R., Aurello, P., D’Angelo, F., Pezzoli, F., Rossi, S., Pilozzi, E., Ercolani, G. and Ravaioli, M. (2006) Giant Hepatic Adenoma with Bone Marrow Metaplasia Not Associated with Oral Contraceptive Intake. World Journal of Surgical Oncology, 4, 58. http://dx.doi.org/10.1186/1477-7819-4-58

[7] Burns, P.N. and Wilson, S.R. (2007) Focal Liver Masses: Enhancement Patterns on Contrast-Enhanced Image- Concordance of US Scans with CT Scans and MR Images 1. Radiology, 242, 162-174. http://dx.doi.org/10.1148/radiol.2421051006

[8] Khan, S.A., Davidson, B.R., Goldin, R., Pereira, S.P., Rosenberg, W.M.C., Taylor-Robinson, S.D., Thillainayagam, A.V., Thomas, H.C., Thursz, M.R. and Wasan, H. (2002) Guidelines for the Diagnosis and Treatment of Cholangiocarcinoma: Consensus Document. Gut, 51, vi1-vi9. http://dx.doi.org/10.1136/gut.51.suppl_6.vi1

[9] Befeler, A.S. and Di Bisceglie, A.M. (2002) Hepatocellular Carcinoma: Diagnosis and Treatment. Gastroenterology, 122, 1609-1619. http://dx.doi.org/10.1053/gast.2002.33411

[10] Stewart, B.W. and Kleihues, P. (2003) International Agency for Research on C. World Cancer Report. IARC Press, Lyon.

[11] Turgut, A.T., Akhan, O., Bhatt, S. and Dogra, V.S. (2008) Sonographic Spectrum of Hydatid Disease. Ultrasound Quarterly, 24, 17-29. http://dx.doi.org/10.1097/RUQ.0b013e318168f0d1

[12] Haque, A., Sadaque, A.S.Q.M., Hossain, I. and Islam, Q.T. (1998) Sonographi Study of 50 Cases of Hepatic Masses. Bangladesh Journal of Radiology and Imaging, 6, 53-56.

[13] Ahmed, F. (1996) Sonogram Analysis of 1500 HBS Patients. Bangladesh Journal of Radiology and Imaging, 4, 58-61.

[14] Kang, B.K., Lim, J.H., Kim, S.H., Choi, D., Lim, H.K., Lee, W.J. and Lee, S.J. (2003) Preoperative Depiction of Hepatocellular Carcinoma: Ferumoxides-Enhanced MR Imaging versus Triple-Phase Helical CT 1. Radiology, 226, 79-85. http://dx.doi.org/10.1148/radiol.2261011827

[15] Snow, Jr., J.H., Goldstein, H.M. and Wallace, S. (1979) Comparison of Scintigraphy, Sonography, and Computed Tomography in the Evaluation of Hepatic Neoplasms. American Journal of Roentgenology, 132, 915-918. http://dx.doi.org/10.2214/ajr.132.6.915

[16] Parveen, S. (2000) Role of Ultrasound and CT in the Evaluation of Space Occupying Lesions in Liver Prospective Study with Histopathological Correlation. MD Thesis, Bangabandhu Sheikh Mujib Medical University, Dhaka. 